\title{
Gas Diffusion-Flow Injection System with Preconcentration for the Analysis of Fluoride in Semen
}

\section{Humberto Gómez-Ruiz ${ }^{1 *}$ (D), Lucia Hernández G $^{1}$ (D), Fernando Díaz Barriga ${ }^{2}$ and María Deogracias Ortiz-Pérez ${ }^{2}$}

${ }^{1}$ Facultad de Química, UNAM, Ciudad Universitaria, México

${ }^{2}$ Facultad de Medicina, UASLP, México

\begin{abstract}
Among the deleterious effects of fluorine in the human body is the alteration of the reproductive system. The measurement of fluoride in urine is usually used as a biomarker of exposure but it provides no information about is incorporation in the reproductive system. So, in order to relate fluoride with effects in male's fertility it is convenient to measure fluoride in semen.

Fluorine is one of the elements whose determination is difficult because the final measurement of the fluoride ion is interfered by other species usually present in the samples. For this reason, separation by distillation of the fluoride as hydrofluoric acid prior to its determination is commonplace. Separation of fluoride by distillation is time-consuming, so new methods are aimed to avoid the distillation step.

Biological samples normally contain low levels of fluorine, so it is always necessary a preconcentration step before the determination, but in the case of semen the sample volume is typically low (not more than $3 \mathrm{ml}$ ). So, the main goal was the determination of low levels of fluorine in a small sample volume of biological fluids.

We developed a method using and automated FIA (Flow Injection Analysis) system using a gas diffusion cell (GDC) that can be operated in two ways a) Continuous for samples with high concentration and b) An open/close configuration for samples with low concentration. The method is based on the conversion of the fluoride ion to the HMDS derivative (a gas) and permeating the gas through a membrane regenerating the fluoride ion in the acceptor current and measuring it with an Ion Selective Electrode (ISE). The method allows the measurement of fluoride in semen with low detection limits, low sample volume, but allowing a good reliability measured as \%RSD: $1.6 \%$ RSD for semen samples in the open-closed configuration and $0.68 \%$ RSD for the continuous mode.

The method was used in the determination of fluoride in semen of 28 individuals from San Luis Potosí, México, exposed to low concentrations of fluoride (drinking water) and a subgroup of occupationally exposed workers with high concentrations of fluoride (laboral exposure) but also to drinking water.
\end{abstract}

\section{Keywords}

Fluoride, Semen, FIA, Gas diffusion cell

\footnotetext{
*Corresponding author: Humberto Gómez-Ruiz, Facultad de Química, UNAM, Ciudad Universitaria, CP 04510, México D.F, México, Tel: +52-(55)-56-22-37-86

Accepted: May 26, 2020; Published: May 28, 2020

Copyright: (c) 2020 Gómez-Ruiz H, et al. This is an open-access article distributed under the terms of the Creative Commons Attribution License, which permits unrestricted use, distribution, and reproduction in any medium, provided the original author and source are credited. Gómez-Ruiz et al. Int J Analyt Bioanalyt Methods 2020, 2:009
} 


\section{Introduction}

It has reported that about 1.5 million of Mexicans are exposed to high levels of fluoride (1500 $\mathrm{mg} / \mathrm{L}$ ) in drinking water [1] This constitutes a serious health issue.

Among the toxicological effects of fluoride is the alteration of the reproductive system, from the damage in the mitochondrial DNA in sperm of mice [2], to the alteration of reproductive hormones in humans [3] or the loss in fertility in populations with high levels of fluoride in drinking water [4].

The determination of fluoride has been simplified by the development of ion-selective electrode (ISE) potentiometry, however, ISE must be used carefully and results must be interpreted cautiously, since an ISE may be affected by numerous analytical interferences which may either increase or decrease the apparent analyte concentration, or which may damage the ISE [5]. For this reason, many kinds of samples containing fluoride must be treated before its determination. Separation of fluoride by distillation is time-consuming; moreover, the distillate is so highly diluted by the steam-condensate that the sensitivity of the analysis is lowered significantly [6]. New methods are aimed to eliminate the need of the distillation step. Non-chromatographic continuous separation techniques appear to be a very promising alternative, since they can improve both the sensitivity of a method by including concentration steps and the selectivity by avoiding matrix effects of interferents [7].

To perform such analysis, means many samples that should be processed in short periods of time, so any method development should consider parameters as simplicity, speed, ease of operation, and above all high precision and accuracy. If the results are going to be used to define policies for health improvement.

In the present work, a method for the fluoride determination in biological samples that can operate in two ways: a) Continuous mode for samples with high concentration and b) An open/close mode for samples with low concentration, was developed. The method is based on the conversion of fluoride to the volatile trimethylfluorosilane (TMFS) using hexamethyldisilazane (HMDSA) in an acidic medium. TMFS formed in the reaction evaporates and diffuses through a polypropylene membrane, cased in a diffusion cell (Figure 1), to be absorbed into a sodium hydroxide acceptor stream [8] at the upper part of the diffusion cell. A fluoride-selective electrode then is used for the final measurement of the fluoride ion [9]. This operation mode is the continuous mode. For the fluoride determination at low levels in semen, an open-closed configuration is proposed. The volatile TMFS formed in the lower part of the gas diffusion cell diffuses through the membrane to be absorbed in the stationary acceptor enclosed in the sample loop of a second injection valve, where it is continuously concentrated previous to the measurement in the ISE.

\section{Experimental Section}

\section{Apparatus and instruments}

Four channels Gilson Minipuls-2 and eight chan-

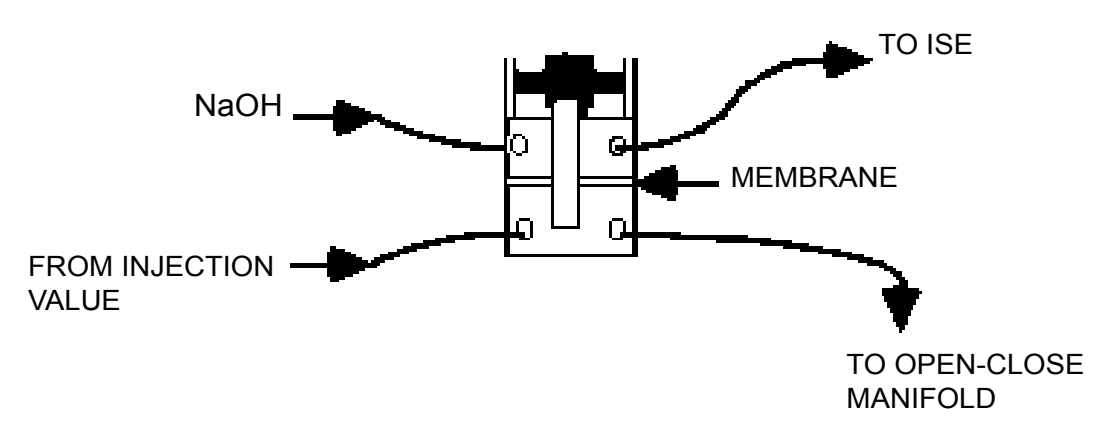

(a)

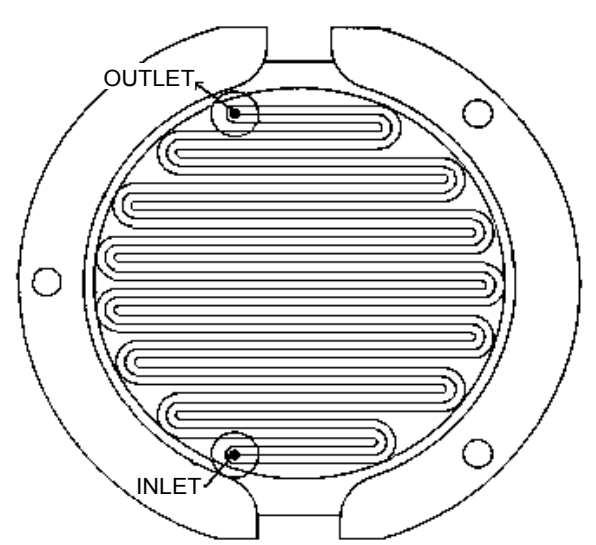

(b)

Figure 1: a) Gas diffusion cell (GDC) consists of two halves made from acrylic, each half having one inlet and one outlet. A polypropylene membrane is cased in a diffusion cell; (b) Inner surface of each half cell. The groove was $0.08 \mathrm{~cm}$ wide and $0.08 \mathrm{~cm}$ deep. 
nels Gilson Minipuls-3 peristaltic pumps, four Rheodyne 5041 low-pressure injection valves (two of them acting as switching valves), PTFE tubing of 0.5 $\mathrm{mm}$ I.D. were used to build the hydrodynamic manifold. An Alpkem Ol Analytical gas diffusion cell with $0.1 \mathrm{~mm} \times 25 \mathrm{~mm}$ polypropylene membrane and an Eppendorf $\mathrm{FH}-40$ column reactor/flow-through heater with Eppendorf TC-45 temperature controller were also employed.

The combination fluoride-selective ion electrode (Orion 960900) was fitted in a flow cell (Figure 2) with an internal volume of $100 \mu \mathrm{L}$. The potential was monitored in a Cole-Parmer digital bench top

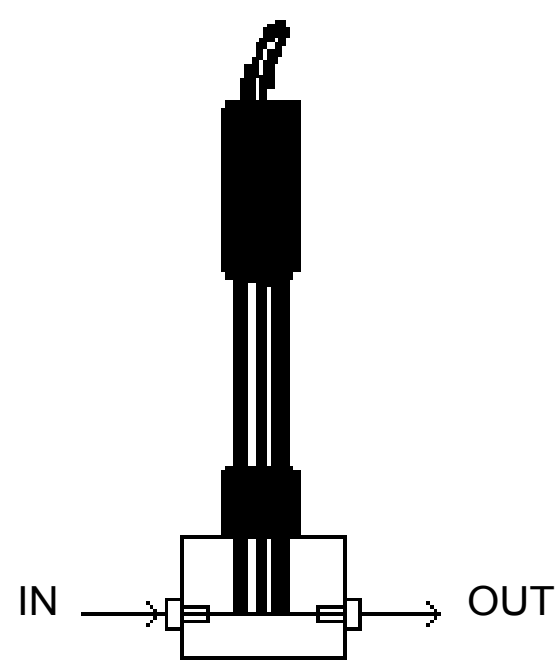

Figure 2: ISE flow cell.
$\mathrm{pH}$ meter coupled to the data analysis of an OI Flow Solution 3000 instrument.

\section{Reagents}

Fluoride Stock solution - A $1000 \mathrm{mg} / \mathrm{L}$ fluoride solution was prepared from sodium fluoride (Merck). Fluoride standards in the range 0.5-10.0 and $0.02-0.10 \mathrm{mg} / \mathrm{L}$ were prepared by appropriate dilutions of the stock solution. A $10 \%(\mathrm{v} / \mathrm{v})$ solution of 1,1,1,3,3,3-hexamethyldisilazane (HMDSA Aldrich) in $2 \mathrm{M} \mathrm{H}_{2} \mathrm{SO}_{4}$ (J.T. Baker) was prepared daily by measuring out a volume of the acid solution into a flask, and adding the appropriate volume of HMD$\mathrm{SA}$ and stirring for 5 minutes. After standing for 15 $\mathrm{min}$, the upper organic layer is discarded, and the aqueous solution is used for the test. A $0.05 \mathrm{M}$ sodium hydroxide (J.T. Baker) solution is used as the acceptor stream. A 0.2 M acetic acid (Merck)-0.1 M potassium chloride (Merck) solution is used in order to keep the $\mathrm{pH}$ and the ionic strength constant.

\section{FIA Manifold and procedure}

Two manifolds were used in the determination. The schematic diagram for the continuous mode is shown in Figure 3. The sample or standard solution is injected in a $2 \mathrm{M} \mathrm{H}_{2} \mathrm{SO}_{4}$ stream and merge with $\mathrm{HMDSA} / \mathrm{H}_{2} \mathrm{SO}_{4}$ solution to form trimethylfluorosilane (TMFS). The reaction takes place in a 300 $\mathrm{cm}$ reactor coil made from Teflon tubing (i.d. $=0.7$ $\mathrm{mm}$, with a coil diameter of $1.5 \mathrm{~cm}$ ) thermostated

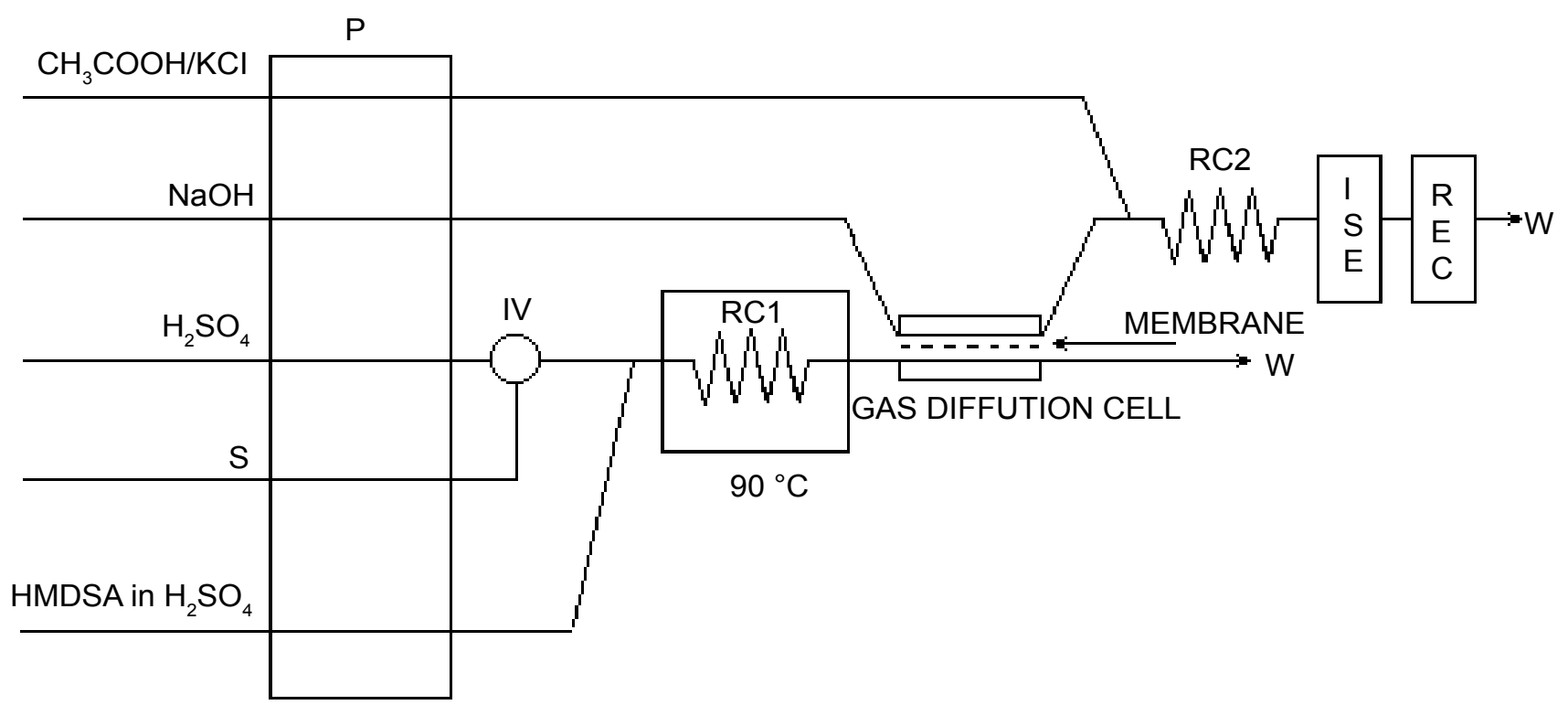

Figure 3: Schematic diagram: Continuous mode.

P: Peristaltic pump; IV: Injection Valve; RC: Reaction Coil; RC1: $300 \mathrm{~cm}, \mathrm{RC} 2: 50 \mathrm{~cm}$; ISE: Fluoride-selective Electrode; REC: Recorder; W: Waste. 


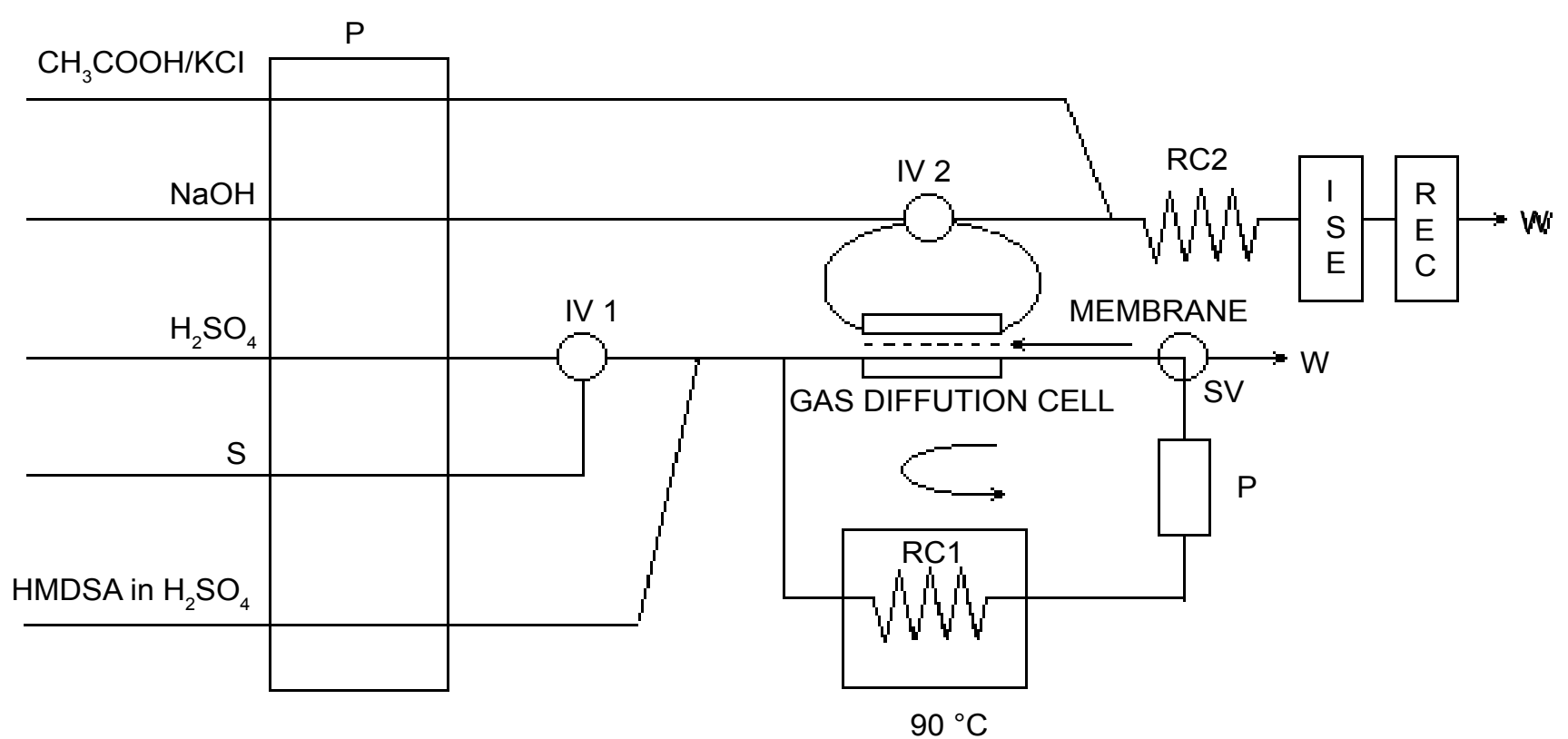

Figure 4: Manifold for the concentration mode.

P: Peristaltic pump; IV: Injection Valve; RC: Reaction Coil; RC1: $300 \mathrm{~cm}, \mathrm{RC2}: 50 \mathrm{~cm}$; ISE: Fluoride-selective Electrode; REC: Recorder; W: Waste. P: Auxiliary pump; SV: Selection Valve.

Table 1: Optimization of variables.

\begin{tabular}{|l|l|l|}
\hline Parameter & $\begin{array}{l}\text { Range } \\
\text { studied }\end{array}$ & $\begin{array}{l}\text { Optimum } \\
\text { value }\end{array}$ \\
\hline HMDSA $(\% \mathrm{v} / \mathrm{v})$ & $1.5-12$ & 10 \\
\hline Temperature $\left({ }^{\circ} \mathrm{C}\right)$ & $60-92$ & 90 \\
\hline Injection volume $(\mu \mathrm{l})$ & $100-750$ & 500 \\
\hline Reaction coil RC1 length $(\mathrm{cm})$ & $100-500$ & 300 \\
\hline Acid solution flow rate $(\mathrm{ml} / \mathrm{min})$ & $0.5-1.3$ & 1.0 \\
\hline Basic solution flow rate $(\mathrm{ml} / \mathrm{min})$ & $1-4$ & 3 \\
\hline Concentration time $(\mathrm{min})$ & $1-4$ & 3 \\
\hline
\end{tabular}

at $90{ }^{\circ} \mathrm{C}$. The volatile TMFS formed is directed to the lower part of the gas diffusion cell, where it diffuses through the polypropylene membrane and is redissolved by the $\mathrm{NaOH}$ stream. The outlet of the upper part of the gas diffusion cell is merged with the $\mathrm{CH}_{3} \mathrm{COOH}-\mathrm{KCl}$ stream and moves toward the detector.

When the concentration (open/close) mode is used, the acceptor portion of the gas diffusion module constitutes the injector sample loop of the injector valve 2 (IV2). The sample or standard solution is injected with the injection valve 1 (IV1) in a $2 \mathrm{M} \mathrm{H}_{2} \mathrm{SO}_{4}$ stream, and merge with HMDSA/ $\mathrm{H}_{2} \mathrm{SO}_{4}$ solution to form the TMFS in the $300 \mathrm{~cm}$ coil thermostated at $90{ }^{\circ} \mathrm{C}$, as shown in the lower half of the manifold of Figure 4. After 1:30 min has elapsed, before the injection, the selection valve (SV) is switched to maintain the system closed. The volatile TMFS formed is directed to the lower part of the gas diffusion cell, diffuses through the membrane to be absorbed in the stationary acceptor stream enclosed in the sample loop of the IV2, where it is concentrated. The plug of sample or standard solution in the closed system passes through the thermostated coil and the gas diffusion cell iteratively for a predetermined time (Table 1). After the required concentration time, the IV2 is switched to the inject position, the carrier passes through the sample loop, flushes out the fluoride and merge with the $\mathrm{CH}_{3} \mathrm{COOH}-\mathrm{KCl}$ stream for its potentiometric determination in the upper half of the manifold. SV1 is then switched to the open position so that the loop can be refilled with fresh HMDSA/ $\mathrm{H}_{2} \mathrm{SO}_{4}$ solution and another fluoride injection can take place.

\section{Results and Discussion}

\section{Chemistry of the reaction}

The reaction for generation of the volatile compound is: $\mathrm{NH}_{4}^{+}$

$2\left[\left(\mathrm{CH}_{3}\right)_{3} \mathrm{Si}\right]_{2} \mathrm{NH}+4 \mathrm{HF}+2 \mathrm{H}^{+} \rightarrow 4\left(\mathrm{CH}_{3}\right)_{3} \mathrm{SiF}+2$

The chemical reaction of the absorption of TMFS in the basic solution is: 


$$
2\left(\mathrm{CH}_{3}\right)_{3} \mathrm{SiF}+2 \mathrm{OH}^{-} \rightarrow\left[\left(\mathrm{CH}_{3}\right)_{3} \mathrm{Si}\right]_{2} \mathrm{O}+\mathrm{F}^{-}+\mathrm{H}_{2} \mathrm{O}
$$

The reactions thermodynamics favor the formation of products in both cases. Because FIA measurements do not require that equilibrium be reached, it is important that the reaction rapidly generates enough concentration of products.

\section{Optimization}

The optimization of the method included the study of a series of variables grouped in those related to the chemical characteristics (HMDSA concentration), physical (temperature) and due to the dynamic system (volume of injection, flowrate, and reactor length). Range and optimum values of these variables are listed in Table 1.

The HMDSA solution was first prepared according with what was reported by I. Papaefstathiou, et al. and TJ Cardwell, et al. [8,9] for standards and samples prepared in aqueous solutions, the concentration of HMDSA where adequate, but in the case of semen samples it was not enough, and the recovery of fluoride ion in samples with standard additions in the open configuration produced lower values than what was expected.
The length of the thermostated reaction coil was studied in an interval between 100 and 330 $\mathrm{cm}$. Reactors longer than $300 \mathrm{~cm}$ did not improve the increment in the signal.

The effect of the flowrates of the donor and the acceptor streams and the injection volume was also studied and optimized.

The optimal conditions for semen samples were: Injection volume $500 \mu \mathrm{l}$, HMDSA concentration $10 \% \mathrm{v} / \mathrm{v}$, reaction coil RC1 length $300 \mathrm{~cm}, \mathrm{RC} 1$ temperature $90{ }^{\circ} \mathrm{C}$, acid solution flow rate $1.0 \mathrm{ml} / \mathrm{min}$ and basic solution flow rate $3 \mathrm{ml} / \mathrm{min}$.

With the optimized method, standard solutions of fluoride in the range $0.2-1 \mathrm{mg} / \mathrm{L}$ were injected. Graph 1 show the calibration curve obtained by plotting measured potential $(\mathrm{mV})$ as a function of the logarithm of fluoride concentration. The relative standard deviation calculated with the signal obtained of 11 injections of solution $0.6 \mathrm{mg} / \mathrm{L} \mathrm{F}^{-}$is $0.68 \%$ RSD.

\section{Open-closed FIA configuration: Concentration mode}

To allow the enrichment/concentration of the

Table 2: Calibration curves for fluoride.

\begin{tabular}{|l|l|l|l|l|}
\hline Mode & R & Dynamic range (mg/L) & Detection limit (mg/L) & \%RSD \\
\hline Continuous & 0.99993 & $0.2-1$ & 0.162 & 0.68 \\
\hline Concentration (open/close) & 0.99884 & $0.02-0.4$ & 0.018 & 1.6 \\
\hline
\end{tabular}

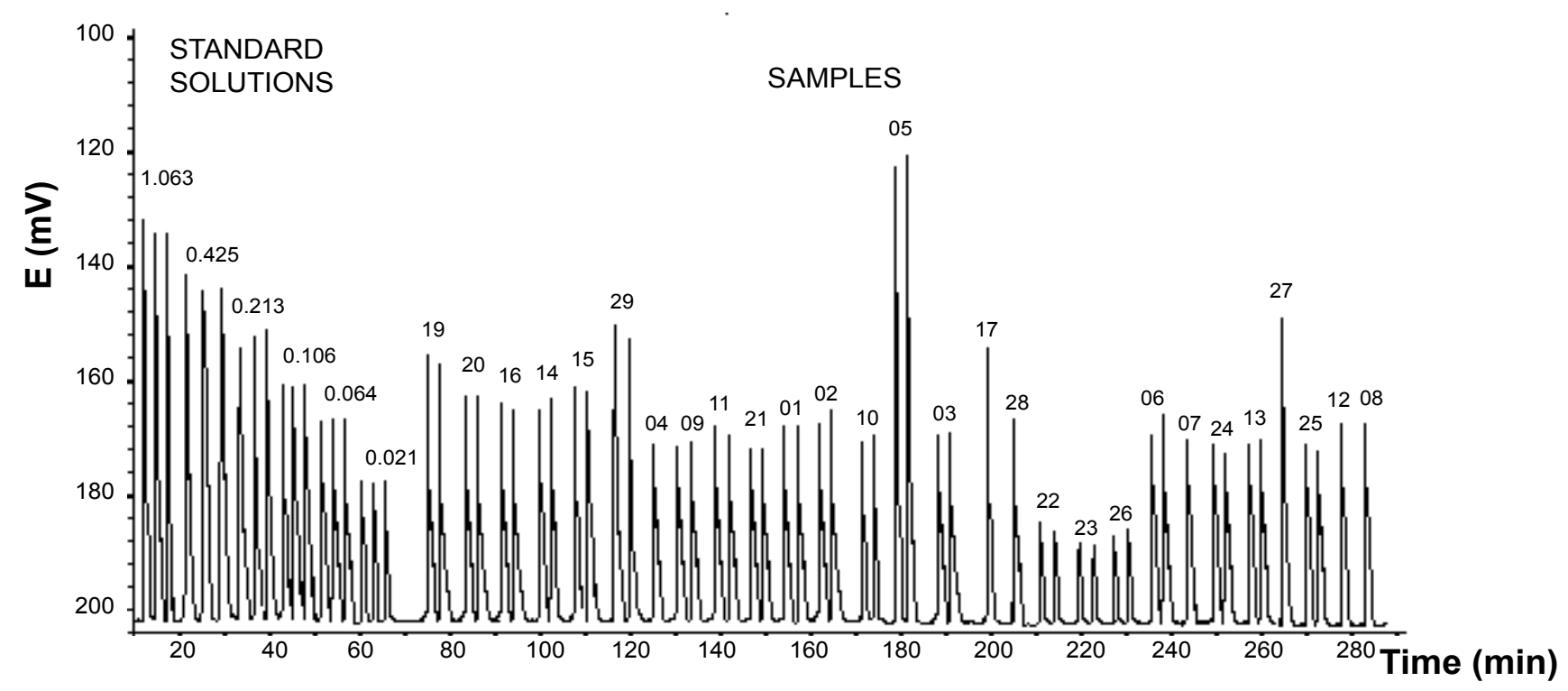

Figure 5: Signals obtained with fluoride standards solutions and semen samples. The numbers on the standard peaks correspond to $\mathrm{mg} / \mathrm{L}$ of fluoride, and the numbers on the sample peaks correspond to sample identification number. 
Table 3: Results obtained by application of the method for the analysis of fluoride in semen samples.

\begin{tabular}{|l|l|}
\hline Sample & Concentration $(\mathbf{m g} \mathbf{F} / \mathbf{L})$ \\
\hline 01 HSM & 0.049 \\
\hline 02 JZB & 0.074 \\
\hline 03 AH & 0.044 \\
\hline 04 CAA & 0.043 \\
\hline 05 VH & $3.132^{*}$ \\
\hline 06 JJC & 0.048 \\
\hline 07 MVL & 0.041 \\
\hline 08 RCC & 0.060 \\
\hline 09 JRRM & 0.044 \\
\hline 10 JCO & 0.039 \\
\hline 11 AGC & 0.046 \\
\hline 12 RL & 0.059 \\
\hline 13 MPB & 0.041 \\
\hline 14 IG & 0.066 \\
\hline 15 JLMR & 0.091 \\
\hline 16 RRR & 0.063 \\
\hline 17 JBO & 0.197 \\
\hline 19 NM & 0.123 \\
\hline 20 MML & 0.082 \\
\hline 21 FDB & 0.042 \\
\hline 22 JM & $<0.02$ \\
\hline 23 AT & $<0.02$ \\
\hline 24 INPM & $<0.02$ \\
\hline $25 \mathrm{MAV}$ & 0.038 \\
\hline 26 JLGD & $<0.02$ \\
\hline 27 ORS & 0.302 \\
\hline 28 JAM & 0.055 \\
\hline 29 ARM & 0.210 \\
\hline \\
\hline
\end{tabular}

${ }^{*}$ Concentration calculated with a different calibration curve (1-8 mg/L F).

fluoride ion in the basic solution stream, keeping constant the flow at the surface of the electrode to avoid irreproducibility of the sensor response due to changes in the ionic strength, the injection valve IV2 was positioned in so that there is always a continuous flow of the electrolyte solution through the ISE. In the filling position of this valve the flow through the system is continuous, except in the loop of the valve, which constituted the upper part of the diffusion cell; the flow through is restored by switching the valve to the inject position, after the required concentration time.
A concentration time of $3 \mathrm{~min}$., corresponding to 4 cycles of iterative pass of the plug through the thermostated coil and the gas diffusion cell, under these conditions the highest signal and the best results were obtained.

Graph 2 shows the calibration curve obtained by plotting measured potential $(\mathrm{mV})$ as a function of the logarithm of fluoride concentration. The relative standard deviation calculated with the signal obtained of 11 injections of solution $0.06 \mathrm{mg} / \mathrm{L} \mathrm{F}^{-}$is $1.6 \%$ RSD.

The results obtained in terms of dynamic range, correlation coefficient, detection limit and precision for the proposed method, with and without concentration are listed in Table 2.

\section{Application of the method to real samples}

To show the applicability of the method, samples from workers on the San Luis Potosi area where analyzed. Figure 5 show signals obtained with fluoride standards solutions and semen samples Table 3 resumes the values of fluoride obtained in 28 samples, in all the cases the concentration mode was used. In the case of sample $05 \mathrm{VH}$ the values where so large that a new calibration curve was prepared in the range 1 to $8 \mathrm{mg} \mathrm{F} / \mathrm{L}$ for this sample so to measure the concentration of fluoride.

\section{References}

1. Alarcón-Herrera MT, Martin-Alarcon DA, Gutiérrez $M$, Reynoso-Cuevas L, Martín-Domínguez $A$, et al. (2020) Co-occurrence, possible origin, and healthrisk assessment of arsenic and fluoride in drinking water sources in Mexico: Geographical data visualization. Science of the Total Environment 698: 1-8.

2. Zilong $S$, Xingchen $X$, Yuliang $Z$, Ruiyan $N$, Jundong $W$ (2017) Effect of sodium fluoride on the sperm mitochondrial DNA in mice. Biochemical and Biophysical Research Communications 492: 295-299.

3. Ortiz-Pérez $D$, Rodríguez-Martínez $M$, Martínez $F$, Borja-Aburto VH, Castelo J, et al. (2003) Fluoride-induced disruption of reproductive hormones in men. Environ Res 93: 20-30.

4. Humayun K, Ashok KG, Subhasish T (2020) Fluoride and human health: Systematic appraisal of sources, exposures, metabolism, and toxicity. Critical Reviews in Environmental Science and Technology 50: 11161193.

5. (1996) Potentiometric determination of fluoride in aqueous samples with ion-selective electrode. USEPA method, 9214. 
6. Minoru Y, Miyoko K, Noriko M, Takashi K (1979) Separation and concentration of fluoride by distillation with hexamethyldisiloxane. Analytica Chimica Acta 106: 95-102.

7. Valcárcel M, Luque de Castro MD (1991) Non-chromatographic continuous separation techniques. Royal Society of Chemistry, Cambridge, England.

8. Cardwell TJ, Cattrall RW, Mitri M (1994) Gas diffu- sion with preconcentration for the determination of fluoride in water samples by flow injection. Talanta 41: 115-123.

9. Papaefstathiou I, Tena MT, Luque de Castro MD (1995) On-line pervaporation separation process for the potentiometric determination of fluoride in "dirty" samples. Anal Chim Acta 308: 246-252. 


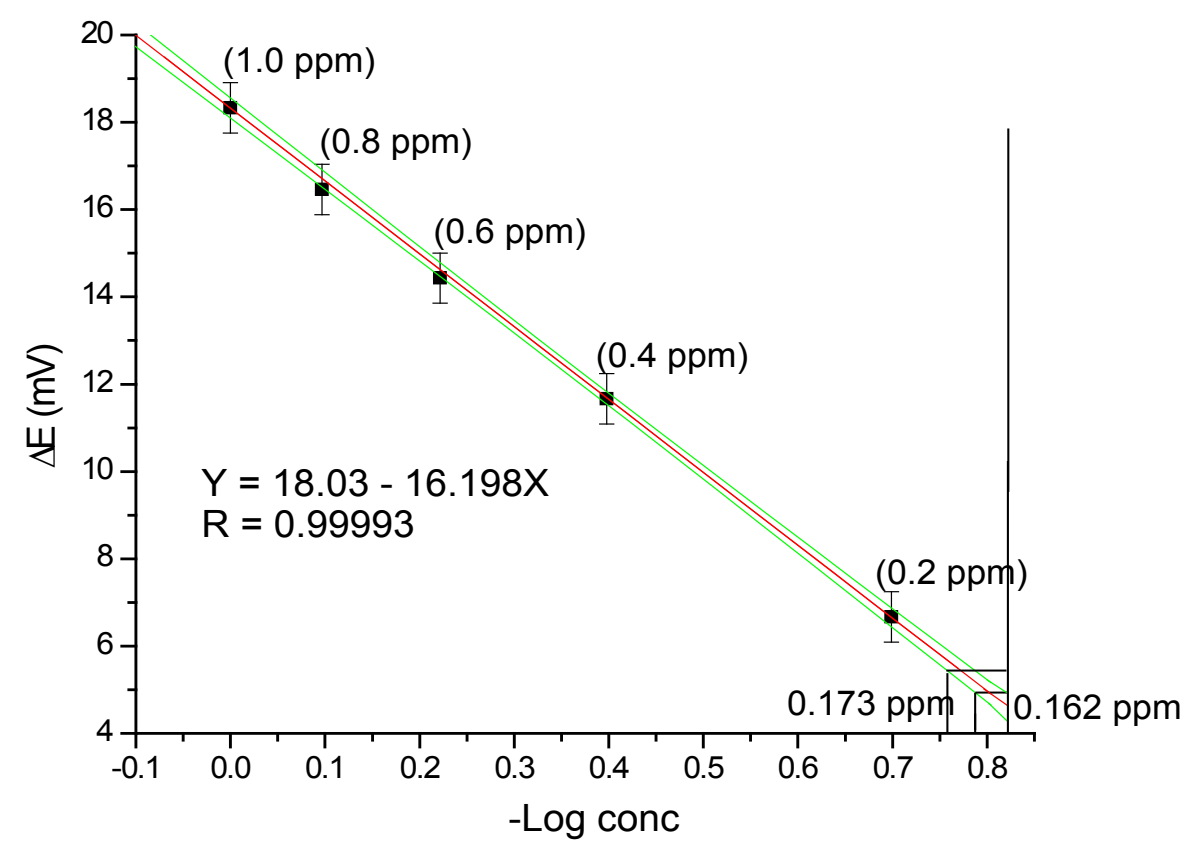

Graph 1: Calibration curve for fluoride determination in continuous mode with the corresponding detection (0.162 ppm) and quantitation (0.173 ppm) limits.

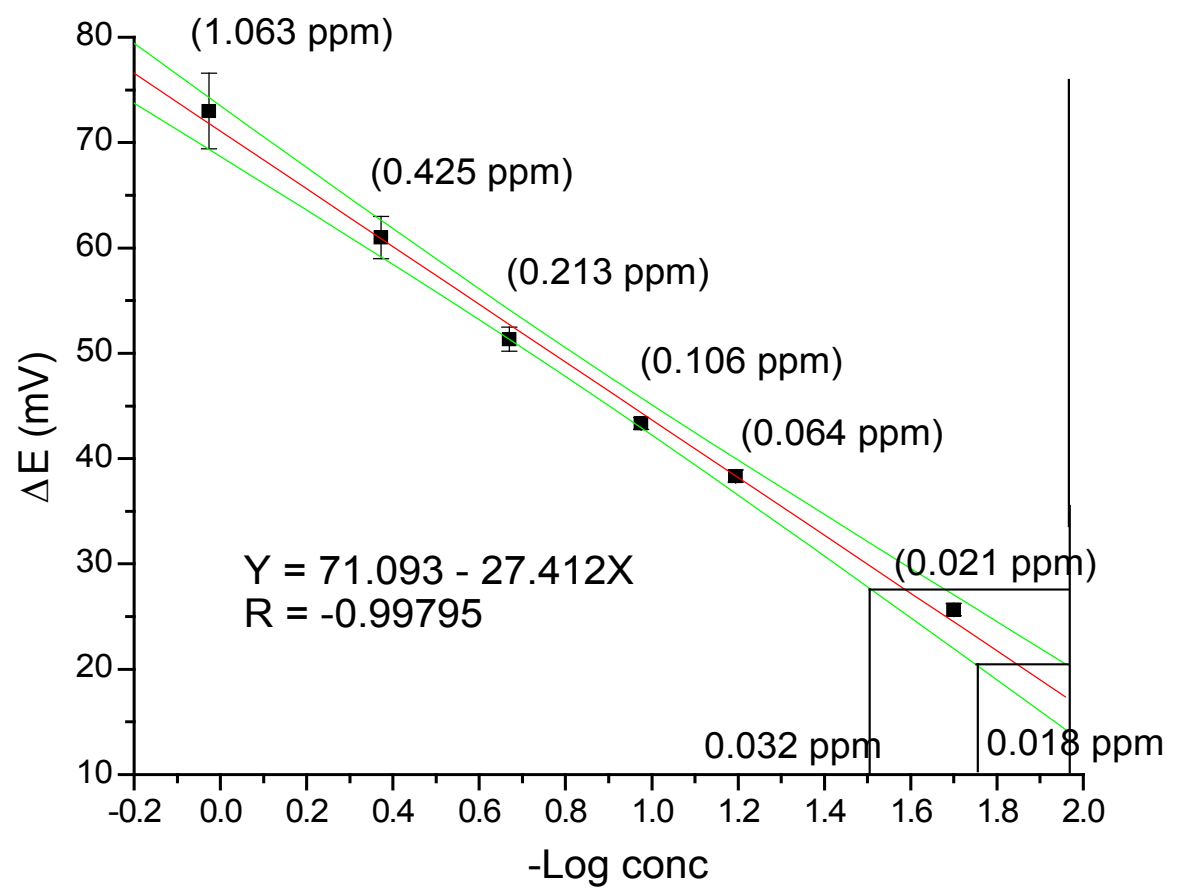

Graph 2: Calibration curve for fluoride determination in preconcentration mode with the corresponding detection $(0.018 \mathrm{ppm})$ and quantitation $(0.032 \mathrm{ppm})$ limits. 